\title{
Ionospheric multiple stratifications and irregularities induced by the 2011 off the Pacific coast of Tohoku Earthquake
}

\author{
Takashi Maruyama ${ }^{1}$, Takuya Tsugawa ${ }^{1}$, Hisao Kato ${ }^{1}$, Akinori Saito ${ }^{2}$, Yuichi Otsuka ${ }^{3}$, and Michi Nishioka ${ }^{3}$ \\ ${ }^{1}$ National Institute of Information and Communications Technology, 2-1 Nukuikita 4-chome, Koganei, Tokyo 184-8795, Japan \\ ${ }^{2}$ Department of Geophysics, Graduate School of Science, Kyoto University, Kitashirakawa-Oiwake-cho, Sakyo-ku, Kyoto 606-8502, Japan \\ ${ }^{3}$ Solar-Terrestrial Environment Laboratory, Nagoya University, Furo-cho, Chikusa-ku, Nagoya 464-8601, Japan
}

(Received April 8, 2011; Revised May 19, 2011; Accepted June 7, 2011; Online published September 27, 2011)

\begin{abstract}
A strong earthquake with a magnitude of 9.0 occurred at 1446:23 JST on March 11, 2011, in Japan. Ionospheric disturbances were detected at 1500 JST at four ionosonde stations. An irregular distortion of echo trace was observed at Kokubunji, which is the nearest station to the epicenter and is $440 \mathrm{~km}$ from it. Multiple-cusp-type trace indicating extra stratification was observed at Wakkanai and Yamagawa, which are 870 and $1410 \mathrm{~km}$ away from the epicenter. A small wavy fluctuation was observed at Okinawa $1910 \mathrm{~km}$ away from the epicenter. The real height analysis of the ionograms showed a vertical structure with a scale size of $20 \sim 30 \mathrm{~km}$.
\end{abstract}

Key words: Ionospheric disturbance, earthquake, $F_{1}$ cusp enhancement, intermediate layer, stratification.

\section{Introduction}

Perturbation of the ionosphere can occur after earthquakes by way of dynamic coupling between seismic waves and the atmosphere (e.g., Shinagawa et al., 2007). Disturbances in the ionospheric total electron content (TEC) are often reported associated with strong earthquakes (Heki and Ping, 2005; Heki et al., 2006; Liu et al., 2006; Otsuka et al., 2006).

TEC measurement using radio signals transmitted from GPS satellites has a large advantage of high time and spatial resolutions. However, it is not very easy to detect any vertical structure because TEC values are an integrated quantity along the radio propagation path penetrating the ionosphere.

On the other hand, ionosondes are limited in their number and location and usually they are programmed to run at intervals of several tenths of minutes. Despite such disadvantages their high capability in measuring vertical structure is expected to compensate TEC measurements. However, observations of earthquake-induced ionospheric deformation in ionograms are quite rare and almost nothing has been reported except in the case of the $M 9.2$ Alaska earthquake in 1964 (Leonard and Barnes, 1965).

A strong earthquake with a magnitude of 9.0 occurred off the Pacific coast of Tohoku at 1446:23 JST (UT+9 hr) on March 11, 2011. Associated with the earthquake, striking ionospheric disturbance was observed. This paper describes ionospheric disturbances in ionograms obtained at four locations over Japan.

Copyright (C) The Society of Geomagnetism and Earth, Planetary and Space Sciences (SGEPSS); The Seismological Society of Japan; The Volcanological Society of Japan; The Geodetic Society of Japan; The Japanese Society for Planetary Sciences; TERRAPUB.

doi: $10.5047 /$ eps.2011.06.008

\section{Ionospheric Measurements}

Figure 1 shows a $\triangle T E C$ map, showing the deviation of TEC from a smoothed background, (Tsugawa et al., 2011) as measured by the GPS receiver network, GEONET, in the center, and ionograms for the four stations at around 1445 JST (0545 UT) just prior to the earthquake. The operation of the four ionosondes are programmed with a small time shift from the nominal time stamp of each quarter hour by $-105,-30,+45$, and $+120 \mathrm{~s}$ for Wakkanai $\left(45.16^{\circ} \mathrm{N}\right.$, $\left.141.75^{\circ} \mathrm{E}\right)$, Kokubunji $\left(35.71^{\circ} \mathrm{N}, 139.49^{\circ} \mathrm{E}\right)$, Yamagawa $\left(31.2^{\circ} \mathrm{N}, 130.62^{\circ} \mathrm{E}\right)$, and Okinawa $\left(26.68^{\circ} \mathrm{N}, 128.15^{\circ} \mathrm{E}\right)$, respectively. The sweep rate of the ionosondes is $2 \mathrm{MHz} / \mathrm{s}$. In the three ionograms except for Wakkanai, sporadic $E$ traces separated into $\mathrm{O}$ - and $\mathrm{X}$-modes were observed and these traces are not a signature of disturbance. A large retardation of the trace near $3 \mathrm{MHz}$ at Wakkanai corresponds to the $E$-layer critical frequency $\left(f_{\mathrm{O}} E\right)$, and a kink near $5 \mathrm{MHz}$ at Yamagawa is the $F_{1}$ cusp; both the signatures are also normal.

\subsection{Perspective of the disturbance}

Figure 2 shows data in the same format as Fig. 1, approximately $14 \mathrm{~min}$ after the earthquake. Striking TEC disturbance forming a concentric ring pattern and patchy disturbance are observed near $36^{\circ} \mathrm{N}$. The center of the concentric ring is shifted from the epicenter as shown by the red star (Tsugawa et al., 2011). Because we are discussing ionospheric signatures, the center of the ring pattern is considered to be a source of the atmospheric disturbance and is referred to as the ionospheric epicenter, which is shown by the cross in the $\triangle$ TEC map. Distances of the ionosonde location from the ionospheric epicenter are $440 \mathrm{~km}$ (Kokubunji), $870 \mathrm{~km}$ (Wakkanai), $1410 \mathrm{~km}$ (Yamagawa), and $1910 \mathrm{~km}$ (Okinawa), the corresponding ionograms are shown counterclockwise from the bottom right. Detailed analysis of the ionogram at each location is presented as follows in the order of distance from the epi- 


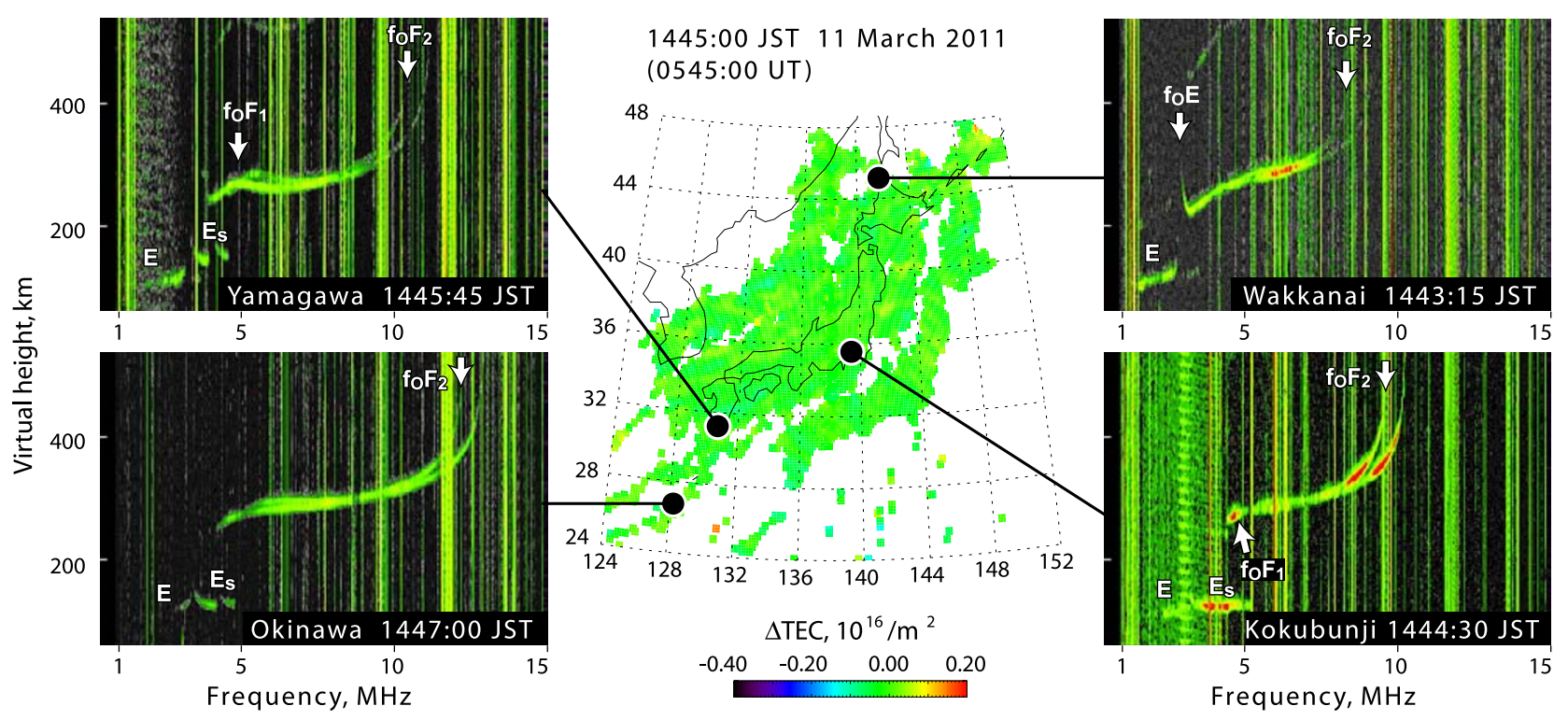

Fig. 1. Ionospheric signature prior to the earthquake. The map in the center shows the TEC disturbance (Tsugawa et al., 2011) and the four ionograms are for Kokubunji (bottom right), Wakkanai (top right), Yamagawa (top left), and Okinawa (bottom left) in the order of distance from the epicenter.
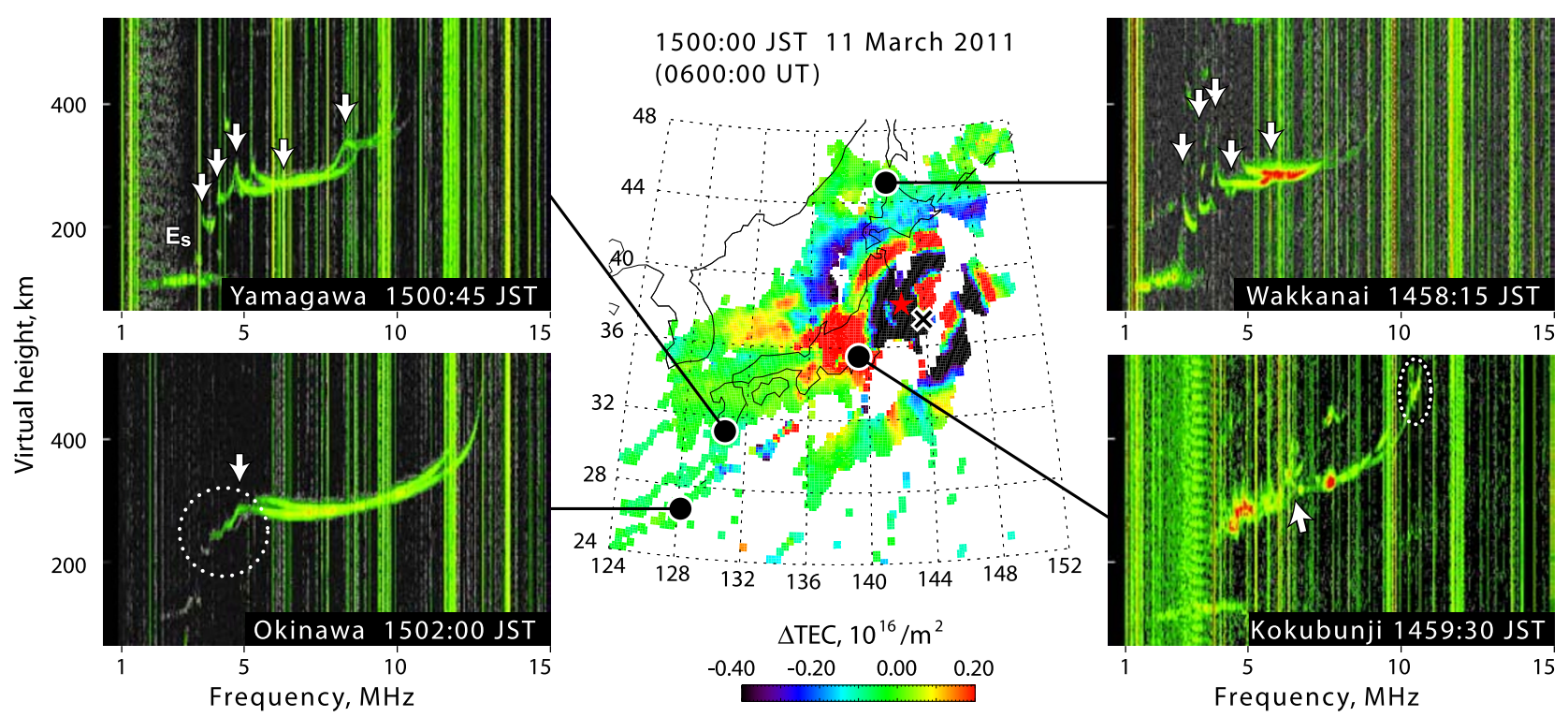

Fig. 2. The same as Fig. 1 but approximately $14 \mathrm{~min}$ after the earthquake. Note that the ionogram times delayed with lowering the latitude and the observation at Okinawa was 2 min after the $\triangle$ TEC map. The arrows indicate a cusp signature for the O-mode trace. The red star in the TEC map is the epicenter reported by the U.S. Geological Survey, while the cross shows the center of the concentric circle of TEC disturbance (ionospheric epicenter).

centers.

\section{Kokubunji}

The whole $F$ trace showed irregular distortion with a kink near $6.5 \mathrm{MHz}$ as shown by the arrow, above which the trace was split showing a non-vertical reflection (the oblique trace was not fully connected). The frequency of the kink is much higher than the $F_{1}$ cusp normally observed $(\sim 4.5 \mathrm{MHz})$ as shown by the arrow in Fig. 1. Near the critical frequency of the X-mode wave at $10.5 \mathrm{MHz}$, the trace was distorted as circled by the dotted line, which indicates that the disturbance reached the $F_{2}$ peak height at $306 \mathrm{~km}$ determined from the transmission factor, $M_{3000} F_{2}$. The $F_{2}$ peak height was raised by $27 \mathrm{~km}$ as compared with the previous ionogram for 1444:30 JST.

\section{Wakkanai}

Significant disturbance was observed with much more organized traces as compared with Kokubunji. The retardation of the lowest part of the $F$ trace corresponds to $f_{\mathrm{O}} E$ as in the case of the ionogram for 1443:15 JST, except for the height which was lowered by approximately $20 \mathrm{~km}$. The trace was disrupted at $3.4 \mathrm{MHz}$ showing the appearance of a new layer above. The next layer showed an enhanced cusp at $3.96 \mathrm{MHz}$, which is close to the frequency of the normal $F_{1}$ cusp $(4 \sim 4.2 \mathrm{MHz})$ as indicated by ionograms at the same local time on other days. Two more weak cusps were noted at around 4.6 and $5.9 \mathrm{MHz}$ in the $F_{2}$ region. The heights of the discontinuity were determined by the POLAN real height analysis program (Titheridge, 1988). They are 


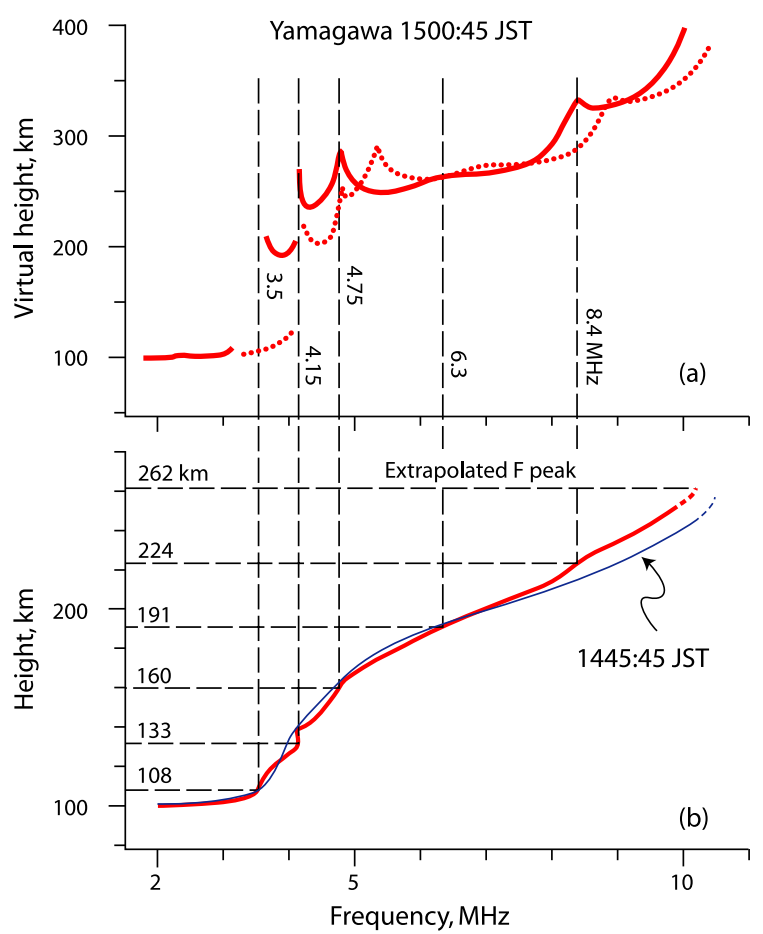

Fig. 3. (a) Sketch of ionogram O-mode trace (solid line) and synthesized $\mathrm{X}$-mode trace (dotted line) from the real height density profile; (b) real height density profile (red line) converted from the scaled O-mode trace shown in panel (a) using POLAN. The blue thin line is the density profile for 1445:45 JST for reference. The electron density is represented by the corresponding plasma frequency $\left(f[\mathrm{~Hz}]=8.98 \sqrt{n_{\mathrm{e}}}\right.$, where $n_{\mathrm{e}}$ is the electron density in $\left.\left[\mathrm{m}^{-3}\right]\right)$ to relate the ionogram and the density profile.

at 105 (E-layer peak), 130, 153, 173, and $199 \mathrm{~km}$. The extrapolated $F_{2}$ peak was at $255 \mathrm{~km}$. (For more details of this analysis, see below for Yamagawa.)

Yamagawa

The disturbance signature was very similar to that of Wakkanai (the O-X mode identification by eye is easier than Wakkanai except in a $6-7.5 \mathrm{MHz}$ range). A weak sporadic $E$ layer blanketed the lowest part of the upper trace in a frequency range $3.44-3.68 \mathrm{MHz}$. A discontinuity can be noted at $4.15 \mathrm{MHz}$ and two well-defined cusps were at 4.75 and $8.40 \mathrm{MHz}$. The first of the two cusps was close to the $F_{1}$ cusp at $\sim 4.6 \mathrm{MHz}$ as noted $\left(f_{\mathrm{O}} F_{1}\right)$ in the ionogram for 1445:45 JST. A careful examination with an assist of POLAN showed another cusp at $6.30 \mathrm{MHz}$.

Figure 3(a) is a sketch of the ionogram showing the scaled O-mode trace (solid line) and the synthesized Xmode trace (dotted line) from the real height density profile. The real height profile was obtained from the O-mode trace by POLAN and O-mode scaling was adjusted until self-consistent $\mathrm{O}$ - and $\mathrm{X}$-mode traces were obtained.

Thus, overlapping traces were resolved in the $6-7.5 \mathrm{MHz}$ range.

Figure 3(b) shows the real height density profiles. The red line corresponds to the ionogram in Fig. 3(a) and the blue thin line is obtained from the previous ionogram for 1445:45 JST.

Comparing the two diagrams, we see that small changes in the vertical density gradient yield large changes in the vir- tual height of ionogram traces, and the characteristic heights were easily determined by combining the two. (The same analysis was conducted for Wakkanai and Okinawa.)

The height of the discontinuities were at 108 ( $E$-layer peak), 133, 160, 191, and $224 \mathrm{~km}$. The extrapolated $F_{2}$ peak was at $262 \mathrm{~km}$.

\section{Okinawa}

The disturbance was weak at Okinawa and the distortion showed a wavy pattern as circled by the dotted line in the bottom left panel of Fig. 2. The heights of the discontinuity were at 111 ( $E$-layer peak), 141, 158, and $175 \mathrm{~km}$. The last cusp was considered to be the normal $F_{1}$ cusp as determined from the ionogram at the same local time on the previous day; the $F_{1}$ cusp was moderately enhanced when compared with the previous frame of the ionogram in Fig. 1.

Thus the disturbance was limited in the $F_{1}$ region, unlike in the case of the other stations.

The extrapolated $F_{2}$ peak was at $298 \mathrm{~km}$.

\subsection{Commencement of the disturbance}

The ionosondes are routinely operated at 15-min intervals. In addition to this, experimental mode soundings are scheduled at $5 \mathrm{~min}$ to each hour at Wakkanai. No disturbance was observed in this extra ionogram for 1455:00 JST at Wakkanai, and the disturbance commenced at 1458:15 JST there. Considering the distance of $870 \mathrm{~km}$ from the ionospheric epicenter, the apparent propagation velocity of the perturbation was estimated to be faster than $1220 \mathrm{~m} / \mathrm{s}$ but slower than $1670 \mathrm{~m} / \mathrm{s}$. If the same velocity is applied to the South-West direction, the disturbance is expected to appear on the ionogram at a time between 1500:30 and 1505:30 JST at Yamagawa, and the actual observation was in the frame of 1500:45 JST as shown in Fig. 2.

Therefore, the times of commencement at Wakkanai and Yamagawa were consistent and the apparent propagation velocity was estimated to be at the faster end of the ambiguity range between 1220 and $1670 \mathrm{~m} / \mathrm{s}$.

At Okinawa, however, the expected time is between 1505:30 and 1512:30 JST and the actual observation was in the frame of 1502:00 JST. The disturbance was observed 3.5 min earlier than the expected time and the apparent velocity was estimated to be $2038 \mathrm{~m} / \mathrm{s}$.

Liu and Sun (2011) determined velocities of seismotraveling ionospheric disturbances induced by the same earthquake for several modes. The velocities are 21003200,900 , and $200 \mathrm{~m} / \mathrm{s}$ for Rayleigh waves, acoustic gravity waves, and tsunami waves, respectively. The commencement of the ionogram signatures of disturbance was close to the range of propagation time of the Rayleigh wave, which might excite atmospheric waves having a slower propagation velocity.

\subsection{Time evolution}

After the ionograms first showed the earthquake-induced disturbances, time evolution of the ionospheric signatures differed from station to station. At Kokubunji, the closest station to the epicenter, the distorted ionogram trace was observed in only one frame of ionogram at 1500 JST. In contrast to this, the distorted ionogram trace continued until 1630 JST at Wakkanai. Well-defined cusps gradually changed to a weak wavy pattern before the disappearance of the disturbance. At Yamagawa, the ionogram trace 
Table 1. Summary of disturbance signatures.

\begin{tabular}{|c|c|c|c|c|c|c|c|c|}
\hline \multirow[b]{2}{*}{ Station } & \multirow[b]{2}{*}{ Distance $(\mathrm{km})$} & \multicolumn{7}{|c|}{ Time* } \\
\hline & & 1500 & 1515 & 1530 & 1545 & 1600 & 1615 & 1630 \\
\hline Kokubunji & 440 & Irreg. & - & - & - & - & - & - \\
\hline Wakkanai & 870 & Cusp & Cusp & Cusp & Cusp & Wavy & Wavy & Wavy \\
\hline Yamagawa & 1410 & Cusp & Wavy & Cusp & Wavy & - & - & - \\
\hline Okinawa & 1910 & Wavy & Wavy & Cusp & - & - & - & - \\
\hline
\end{tabular}

*The actual observation times are shifted depending on the station, see the text for details.

"Irreg.", "Cusp", and "Wavy" stand for irregular distortion of the trace, steep cusp signature, and consecutive weak cusp signature in the ionogram.

once showed a weak wavy pattern at 1515 JST, and multiple enhanced cusps reappeared in the $F_{1}$ and $F_{2}$ regions at $1530 \mathrm{JST}$. After this, the trace returned to a wavy pattern at 1545 JST. At 1600 JST, the disturbance disappeared in the frequency range higher than $4.36 \mathrm{MHz}$, below which sporadic $E$ layer blanketed the $F$ trace. The disturbance at Okinawa was a wavy pattern at 1500 and 1515 JST. The $F_{1}$ cusp was enhanced and a weak cusp appeared in the $F_{2}$ region at $1530 \mathrm{JST}$. The disturbance almost disappeared at 1545 JST.

The time evolution at the four locations is summarized in Table 1.

\subsection{Vertical scale of the disturbance}

At Kokubunji, the disturbance extended from the supposed $F_{1}$ cusp $(\sim 4.7 \mathrm{MHz})$ up to the $F_{2}$ peak 13 min after the quake, though the $F_{1}$ trace was blanketed by the sporadic $E$ layer. The disturbance was significant at lower altitudes.

Ionogram signatures at Wakkanai and Yamagawa at 1500 JST were quite similar to each other such that:

(1) The lowest part of the distortion was between the $E$ layer peak and the $F_{1}$ cusp. The ionogram trace resembled an intermediate layer or high-type sporadic $E$ layer showing an abrupt transition to the upper layer.

(2) A steep cusp was near the $F_{1}$-layer critical frequency $\left(f_{\mathrm{O}} F_{1}\right)$. The $f_{\mathrm{O}} F_{1}$ is mostly determined by a chemical process and shows a small day-to-day variability, unlike $f_{\mathrm{O}} F_{2}$. Therefore, the enhancement of the $F_{1}$ cusp may not be a purely dynamical one but there seems to be contribution of a chemical process including recombination.

(3) Two cusps were in the $F_{2}$ region; a barely-defined one at lower altitude and a moderate one at higher altitude. The vertical separation of the two cusps was 26 and $33 \mathrm{~km}$ at Wakkanai and Yamagawa, respectively. The separation between the enhanced $F_{1}$ cusp and the barely-defined lower cusp in the $F_{2}$ region was 20 and $31 \mathrm{~km}$ at Wakkanai and Yamagawa, respectively.

Although the disturbance at Okinawa was weaker as compared with the other stations, several common features with Wakkanai and Yamagawa were observed. The lowest part of the distortion of the ionogram, a faint segment between 3.6 and $3.9 \mathrm{MHz}$ inside the circle, was the intermediate layer. Comparing the ionograms at 1447:00 and 1502:00 JST, we note that the $F_{1}$ cusp was evidently enhanced.

\subsection{Peculiarity of Kokubunji ionogram}

The ionospheric disturbance at Kokubunji was different in many aspects from the other three stations. The ionogram traces showed irregular distortion only at Kokubunji. The $F$-layer peak was raised by $27 \mathrm{~km}$ in $15 \mathrm{~min}$ at Kokubunji, while it remained at the same level at the other stations. The enhancement of the $F_{1}$ cusp was not seen at Kokubunji. The $\triangle$ TEC map in Fig. 2 shows that there coexisted two types of TEC perturbations; a patchy pattern of TEC enhancement was noted at Kokubunji, which can be distinguished from the concentric pattern. The patchy pattern moved fast out of this area (Tsugawa et al., 2011). The unique signature of the ionogram distortion and its short duration time at Kokubunji might be related to this type of TEC disturbance.

\section{Summary}

The 2011 off the Pacific coast of Tohoku Earthquake occurred at 1446:23 JST (0546:23 UT) on March 11, 2011. Associated with the earthquake, ionospheric disturbance was detected approximately 14 min after the earthquake in quarter-hourly ionograms obtained at four locations from north to south along the Japanese archipelago. The disturbance was characterized by a vertical structure that is difficult to detect by TEC measurement using trans-ionospheric radio waves. Multiple stratifications were observed at Wakkanai, Yamagawa, and Okinawa such that an appearance of an intermediate layer or high-type sporadic $E$ layer, an enhancement of the $F_{1}$ cusp, and additional cusps in the $F_{2}$ region. The vertical scale of the distortion, corresponding to the separation of the two consecutive cusps, was the order of $20 \sim 30 \mathrm{~km}$.

The disturbance at Kokubunji, the closest station to the epicenter, was different in many aspects from the other stations. The ionogram trace showed irregular distortion and the $F$-layer peak was raised by $27 \mathrm{~km}$ after the earthquake. The enhanced $F_{1}$ cusp and the intermediate layer were not observed.

Acknowledgments. The GPS data are provided by the Geospatial Information Authority of Japan. The authors thank J. Uemoto for running POLAN.

\section{References}

Heki, K. and J. S. Ping, Directivity and apparent velocity of the coseismic ionospheric disturbances observed with a dense GPS array, Earth Planet. Sci. Lett., 236, 845-855, 2005.

Heki, K., Y. Otsuka, N. Choosakul, N. Hemmakorn, T. Komolmis, and T. Maruyama, Detection of ruptures of Andaman fault segments in the 2004 great Sumatra earthquake with coseismic ionospheric disturbances, J. Geophys. Res., 111, B09313, doi:10.1029/2005JB004202, 2006. 
Leonard, R. S. and R. A. Barnes, Observation of ionospheric disturbances following the Alaska earthquake, J. Geophys. Res., 70, 1250-1253, 1965.

Liu, J.-Y. and Y.-Y. Sun, Seismo-traveling ionospheric disturbances of ionograms observed during the $2011 M_{\mathrm{w}} 9.0$ Tohoku Earthquake, Earth Planets Space, 63, this issue, 897-902, 2011.

Liu, J.-Y., Y.-B. Tsai, K.-F. Ma, Y.-I. Chen, H.-F. Tsai, C.-H. Lin, M. Kamogawa, and C.-P. Lee, Ionospheric GPS total electron content (TEC) disturbances triggered by the 26 December 2004 Indian Ocean tsunami, J. Geophys. Res., 111, A05303, doi:10.1029/2005JA011200, 2006.

Otsuka, Y., N. Kotake, T. Tsugawa, K. Shiokawa, T. Ogawa, Effendy, S. Saito, M. Kawamura, T. Maruyama, N. Hemmakorn, and T. Komolmis, GPS detection of total electron content variations over Indonesia and Thailand following the 26 December 2004 earthquake, Earth Planets Space, 58, 159-165, 2006.
Shinagawa, H., T. Iyemori, S. Saito, and T. Maruyama, A numerical simulation of ionospheric and atmospheric variations associated with the Sumatra earthquake on December 26, 2004, Earth Planets Space, 59, 1015-1026, 2007.

Titheridge, J. E., The real height analysis of ionograms: A generalized formulation, Radio Sci., 23, 831-849, 1988.

Tsugawa, T., A. Saito, Y. Otsuka, M. Nishioka, T. Maruyama, H. Kato, T. Nagatsuma, and K. T. Murata, Ionospheric disturbances detected by GPS total electron content observation after the 2011 off the Pacific coast of Tohoku Earthquake, Earth Planets Space, 63, this issue, 875879, 2011.

T. Maruyama (e-mail: tmaru@nict.go.jp), T. Tsugawa, H. Kato, A. Saito, Y. Otsuka, and M. Nishioka 